\title{
Outer retinal dysfunction in patients treated with vigabatrin
}

\author{
C.F. Arndt, MD; P. Derambure, MD; S. Defoort-Dhellemmes, MD; and J.C. Hache, MD
}

\begin{abstract}
Article abstract-Objective: To assess early visual impairment related to vigabatrin prospectively in patients with and without visual symptoms. Background: Vigabatrin acts as an inhibitor of gamma-aminobutyric acid (GABA) transaminase. GABA-induced ion transport changes in the retinal pigment epithelium have been described. The electro-oculogram (EOG) is a clinical test that reflects photoreceptor and pigment epithelium function. Patients and methods: Of the 22 consecutive patients presenting with a history of partial seizures currently treated with vigabatrin, 20 were included in the study. A complete clinical ophthalmologic and neurologic examination was performed, including static 100-point perimetry, EOG, and electroretinogram (ERG). Results: In 14 of 20 patients, the light/dark ratio (Arden ratio) of the standard EOG was reduced in at least one eye. The a- and b-wave amplitudes and implicit time of the ERG were within the normal range in all patients; however, ERG oscillatory potentials could not be recorded in 10 patients. Twelve patients had visual field constriction; five complained of visual symptoms. The most severe visual impairment was observed in patients treated with both vigabatrin and valproate. Conclusions: There is some evidence of outer retinal dysfunction in the patients treated with vigabatrin. EOG, a more sensitive diagnostic tool than ERG for screening vigabatrin-treated patients, also appears to be more specific.
\end{abstract}

NEUROLOGY 1999;52:1201-1205

Vigabatrin is an antiepileptic drug (AED) that inhibits gamma-aminobutyric acid (GABA) transaminase, increasing GABA levels in the brain and retina. ${ }^{1}$ Experimental studies of neurotoxicity indicate that, in some species treated with vigabatrin, optic tract damage is present. ${ }^{2}$ However, a clinical, prospective, multicenter study evaluating visual evoked potentials did not find any abnormalities, ${ }^{3}$ suggesting that vigabatrin is safe in humans. By June 1997, however, visual field abnormalities had been reported in 92 of a total estimated number of 140,000 vigabatrin-treated patients. ${ }^{4}$ In all documented cases, ${ }^{4-10}$ visual field constriction appeared to be the common feature. Perimetry provides a sensitive procedure for assessing visual function, but interpretation of therapy-related changes in patients with symptomatic partial epilepsy is difficult, because visual field abnormalities may be linked to cortical lesions. ${ }^{4}$ Providing clinicians with additional tools for visual screening of patients would enable early and accurate diagnosis of preperimetric impairment.

Although pathophysiologic mechanisms remain unclear, there appears to be some electrophysiologic evidence for midretinal photoreceptor dysfunction in patients treated with vigabatrin ${ }^{11}$ and presenting with visual complaints. However, the function of the retinal pigment epithelium (RPE) could also be primarily modified by increased retinal GABA levels, as it has been demonstrated in vitro. ${ }^{12}$ In clinical electrophysiology, the electro-oculogram (EOG) repre- sents the major test for evaluating the RPE and the RPE-photoreceptor outer segment complex.

The purpose of this prospective study was to evaluate whether the EOG might provide an additional diagnostic tool for screening visual functional impairment in patients treated by vigabatrin alone or in association with other AED.

Patients and methods. Patients. All consecutive patients were diagnosed with partial seizures and were on vigabatrin therapy for more than 6 months. Patients with any additional underlying disease that could interfere with the interpretation of the electrophysiologic results were excluded from the study. Other AED that had been discontinued for more than 6 months were not considered when evaluating the results.

Methods. A complete routine ophthalmologic examination was performed in all patients. Visual acuity was determined on a chart first described in the Early Treatment of Diabetic Retinopathy Study. Anterior segment biomicroscopy and applanation tonometry were performed prior to mydriasis. Diagnostic mydriasis was obtained by local instillation of tropicamide $1 \%$ and epinephrine $10 \%$. Retinal biomicroscopy and indirect ophthalmoscopic examination of the retina were performed. Two perimetric procedures were done: a static 100-point 2-dB suprathreshold perimetry and a kinetic Goldmann-based computer-assisted visual field examination (Moniteur Ophtalmologique, Lille, France). In kinetic perimetry, four isopters were tested: 1) the peripheral isopter (III 4e Goldmann equivalent) was presented at a speed of $10 \% \mathrm{sec} ; 2$ ) the two medium isopters, at $5 \%$ sec (III $1 \mathrm{~b}$ and II $1 \mathrm{~b}$ Goldmann equivalent, respectively); 3) the

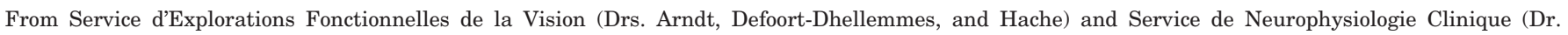
Derambure), Lille, France.

Received October 30, 1998. Accepted in final form February 9, 1999.

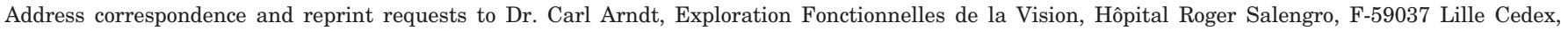
France; e-mail: carndt@univ-lille2.fr 
Table Results of 20 consecutive patients treated with vigabatrin

\begin{tabular}{|c|c|c|c|c|c|c|c|c|c|c|c|c|c|c|c|c|c|}
\hline \multirow[b]{2}{*}{$\begin{array}{l}\text { Pt. } \\
\text { no. }\end{array}$} & \multirow[b]{2}{*}{ Sex } & \multirow[b]{2}{*}{$\begin{array}{c}\text { Age, } \\
\text { y }\end{array}$} & \multirow[b]{2}{*}{$\begin{array}{l}\text { Follow- } \\
\text { up, mo }\end{array}$} & \multicolumn{2}{|c|}{ Vigabatrin } & \multicolumn{2}{|c|}{ Carbamazepine } & \multicolumn{2}{|c|}{ Valproate } & \multirow[b]{2}{*}{ Complaints } & \multicolumn{2}{|c|}{ Visual acuity } & \multicolumn{2}{|c|}{ Visual field } & \multicolumn{2}{|c|}{ EOG } & \multirow[b]{2}{*}{$\begin{array}{c}\text { ERG OP } \\
\text { OD/OS }\end{array}$} \\
\hline & & & & $\begin{array}{c}\text { Dose, } \\
\text { mg }\end{array}$ & $\begin{array}{l}\text { Duration, } \\
\text { mo }\end{array}$ & $\begin{array}{c}\text { Dose, } \\
\text { mg }\end{array}$ & $\begin{array}{c}\text { Duration, } \\
\text { mo }\end{array}$ & $\begin{array}{c}\text { Dose, } \\
\text { mg }\end{array}$ & $\begin{array}{c}\text { Duration, } \\
\text { mo }\end{array}$ & & OD & OS & OD & OS & OD & $\mathrm{OS}$ & \\
\hline 1 & $\mathrm{~F}$ & 45 & 36 & 3,000 & 26 & & & 500 & 13 & & $20 / 20$ & $20 / 20$ & Not per & formed & 146 & 143 & Absent \\
\hline 2 & $\mathrm{~F}$ & 8 & 102 & 1,500 & 12 & & & & & & $20 / 25$ & $20 / 30$ & Normal & Normal & 159 & 159 & Absent \\
\hline 3 & $\mathrm{~F}$ & 29 & 240 & 4,000 & 36 & 1,600 & 36 & & & & $20 / 20$ & $20 / 20$ & Normal & Normal & 151 & 151 & Normal \\
\hline 4 & M & 22 & 12 & 3,000 & 6 & 1,000 & 12 & & & & $20 / 20$ & $20 / 20$ & Normal & Normal & 183 & 130 & Normal \\
\hline 5 & $\mathrm{~F}$ & 20 & 288 & 3,500 & 60 & 1,600 & 120 & & & & $20 / 20$ & $20 / 20$ & Normal & Normal & 183 & 163 & Normal \\
\hline 6 & $\mathrm{~F}$ & 29 & 84 & 3,000 & 12 & & & & & & $20 / 20$ & $20 / 20$ & Normal & Normal & 248 & 225 & Absent \\
\hline 7 & $\mathrm{~F}$ & 26 & 84 & 3,000 & 24 & 1,200 & 60 & & & & $20 / 20$ & $20 / 20$ & Normal & Normal & 145 & 141 & Normal \\
\hline 8 & $\mathrm{~F}$ & 16 & 96 & 2,500 & 36 & 1,400 & 60 & & & & $20 / 20$ & $20 / 20$ & Normal & Normal & 155 & 180 & Normal \\
\hline 9 & $\mathrm{M}$ & 29 & 18 & 3,000 & 8 & 1,600 & 12 & & & Blurring & $20 / 20$ & $20 / 20$ & Mild & Normal & 147 & 161 & Absent \\
\hline 10 & M & 17 & 48 & 3,000 & 36 & 1,200 & 48 & & & & $20 / 20$ & $20 / 20$ & Mild & Normal & 188 & 190 & Normal \\
\hline 11 & M & 34 & 12 & 2,500 & 12 & 1,600 & 12 & & & & $20 / 25$ & $20 / 25$ & Mild & Normal & 195 & 180 & Normal \\
\hline 12 & $\mathrm{~F}$ & 65 & 30 & 2,000 & 28 & & & & & Blurring & $20 / 20$ & $20 / 20$ & Mild & Mild & 242 & 203 & Absent \\
\hline 13 & $\mathrm{~F}$ & 38 & 180 & 3,500 & 36 & 200 & 180 & & & & $20 / 30$ & $20 / 20$ & Mild & Mild & 187 & 193 & Normal \\
\hline 14 & M & 35 & 60 & 1,500 & 12 & 1,600 & 60 & & & Blurring & $20 / 20$ & $20 / 20$ & Mild & Mild & 144 & 150 & Normal \\
\hline 15 & M & 25 & 240 & 3,000 & 24 & 1,200 & 24 & & & & $20 / 20$ & $20 / 30$ & Hemia & nopsia & 223 & 278 & Normal \\
\hline 16 & $\mathrm{~F}$ & 44 & 36 & 3,000 & 24 & 1,400 & 36 & & & & $20 / 20$ & $20 / 20$ & Severe & Severe & 126 & 131 & Absent \\
\hline 17 & $\mathrm{M}$ & 29 & 30 & 4,000 & 24 & & & 2,000 & 24 & Constriction & $20 / 20$ & $20 / 20$ & Severe & Severe & 148 & 145 & Absent \\
\hline 18 & M & 50 & 312 & 3,000 & 180 & 200 & 180 & & & & $20 / 100$ & $20 / 20$ & Severe & Severe & 122 & 143 & Absent \\
\hline 19 & M & 50 & 60 & 2,500 & 60 & 1,000 & 60 & 2,000 & 36 & Constriction & $20 / 30$ & $20 / 20$ & Severe & Severe & 124 & 114 & Absent \\
\hline 20 & M & 43 & 180 & 4,000 & 10 & & & & & & $20 / 20$ & $20 / 20$ & Severe & Severe & 137 & 140 & Absent \\
\hline
\end{tabular}

$\mathrm{OD}=$ right eye $\mathrm{OS}=$ left eye EOG = electro-oculogram $; \mathrm{ERG}=$ electroretinogram $; \mathrm{OP}=$ oscillatory potentials.

central isopter (II 1d Goldmann equivalent); and 4) blind spot detection (III 4e Goldmann equivalent) at $1 \%$ sec. Visual fields with false positive responses of more than $15 \%$, false negative responses, or a rate of fixation loss of more than $20 \%$ were not considered for analysis. In addition, fixation was constantly monitored by an infrared camera and visualized on a television screen. Based on the mean defect and evaluated by static perimetry, the visual fields were classified as normal if the mean defect was below 2.5 $\mathrm{dB}$, as mildly constricted if the mean defect was between $2.75 \mathrm{~dB}$ and $5 \mathrm{~dB}$, and as severely constricted if the mean defect was above $5 \mathrm{~dB}$.

EOG measured the variation of the standing potential of the eye between light $\left(500 \mathrm{~cd} / \mathrm{m}^{2}\right)$ and dark conditions in accordance with the standards of the International Society for Clinical Electrophysiology of Vision (ISCEV). ${ }^{13}$ The patient was instructed to perform target triggered saccades (in the dark, mean luminance of the target: $40 \mathrm{~cd} / \mathrm{m}^{2}$ ). The ratio between the light peak and the dark trough (Arden ratio) was determined in both eyes of each patient. In the laboratory, the lower normal limit of the Arden ratio was at $190 \%$. For this study, patients with an Arden ratio below $185 \%$ in one eye were considered to have an abnormal EOG. Electroretinography (ERG) in scotopic (darkadapted) and photopic (daylight) conditions was performed in accordance with the ISCEV guidelines using unipolar corneal electrodes. ${ }^{14}$ The rod response, maximal response, oscillatory potentials, single flash cone response, and flicker responses were recorded subsequently.
Linear regression was used to investigate the possibility of a linear relationship between mean defect determined by static perimetry and the EOG Arden ratio. One patient with hemianopsia and one unable to perform perimetry were excluded. This analysis was conducted separately for each eye on a base of 18 patients.

Results. A summary of the results is presented in the table. Twenty-two consecutive patients, 11 male and 11 female, with a mean age of $32.7 \pm 13.8$ years (range, 8 to $65)$, all treated with vigabatrin for more than 6 months, were screened for the current study.

Twenty were included and two were excluded because of underlying diseases. One male patient had ocular hypertension and pericentral glaucomatous visual field defects, which would have interfered with the observed perimetric changes due to vigabatrin therapy. One female patient was excluded because of underlying diabetic retinopathy treated by laser, which could modify the results of the EOG. Thus, the analysis was conducted on a base of 20 patients.

The mean duration of treatment with vigabatrin was $12 \pm 4.2$ months (range, 10 to 60 ). All patients had a history of partial seizures at the time of presentation (mean duration of follow-up, $22.3 \pm 19.3$ months). Three patients were treated with vigabatrin alone, 16 with vigabatrin and carbamazepine, 2 with vigabatrin and valproate, and 1 with a combination of vigabatrin, carbamazepine, and valproate. 


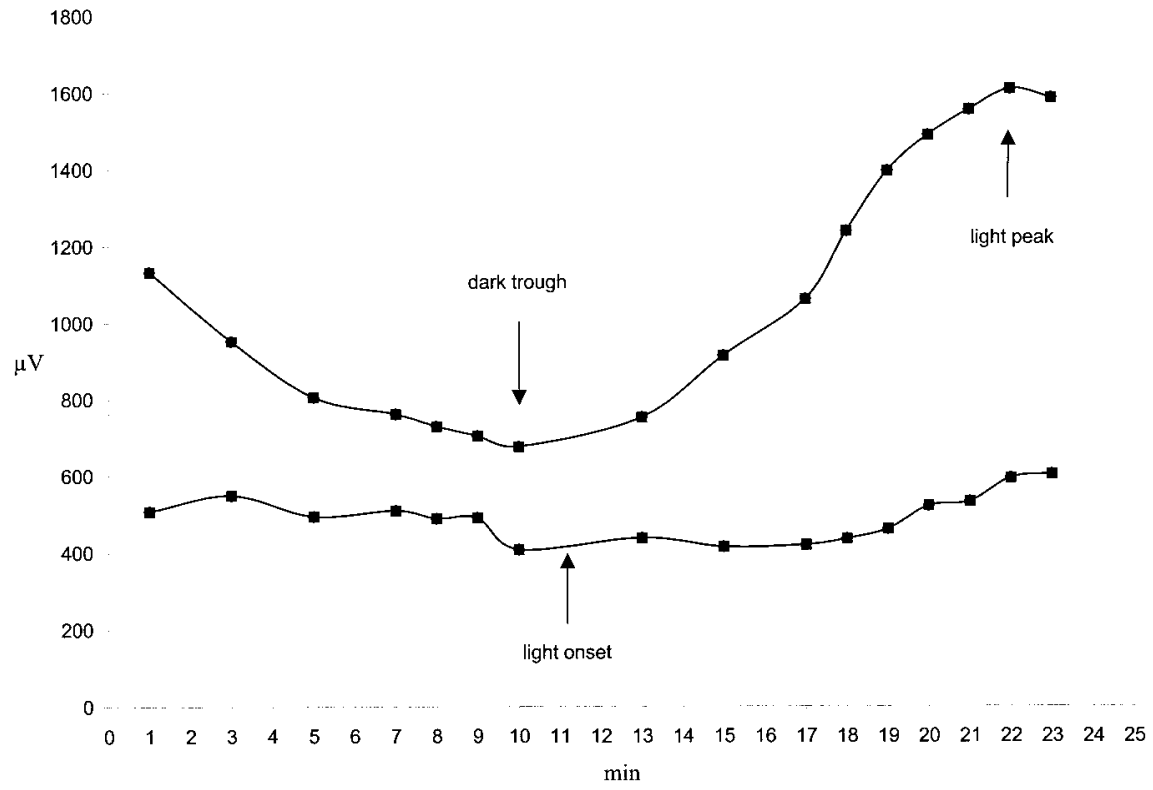

Figure 1. Normal electro-oculogram in Patient 6 (top); abnormal electrooculogram in Patient 17 (bottom).
The mean dosages of vigabatrin, carbamazepine, and valproate were $2,769 \pm 832 \mathrm{mg}$ (range, 1,500 to 4,000 ), $1,300 \pm 424 \mathrm{mg}$ (range, 200 to 1,600), and 1,500 $\pm 866 \mathrm{mg}$ (range, 500 to 2,000), respectively.

Visual symptoms. Of the 20 study patients, 5 presented with a history of visual disturbance: two reported visual field constriction and three had blurred vision. The remaining 15 patients did not have any visual symptoms.

Psychophysical results. Visual acuity. Visual acuity was found to be normal at 20/20 in 32 eyes, 20/25 in 3, 20/30 in 4, and 20/100 in 1 eye presenting with amblyopia.

Visual field testing. In Patient 1 , the visual field examination was unreliable in one eye owing to a high rate of fixation loss. In the other eye, fixation loss was less than $20 \%$, which was nevertheless much higher than in the other patients, all of whom had reliable visual field results. Therefore, the visual fields of Patient 1 were not considered for analysis. Five of the 19 patients presented with severe bilateral visual field constriction. Three patients had bilateral mild constriction; mild visual field constriction was found in only one eye in three additional patients. One patient had hemianopsia, which could be related to occipital head injury. In seven patients, no visual field changes could be detected.

Of the 12 patients with visual field constriction, 5 had visual symptoms. Two patients complained of a peripheral constriction; the other three described their symptoms as visual blurring.

Of the 19 patients who had visual field tests, 11 (58\%) had characteristic visual field constriction in at least one eye.

Electrophysiologic tests. Electro-oculography. Marked impairment of EOG findings could be identified in 14 patients, bilaterally in 13 and unilaterally in 1 (figure 1). The five patients with severe visual field constriction (excluding the patient with hemianopsia and a normal EOG) had markedly abnormal EOG results. Thus, major visual field impairment appeared to be related to a lower EOG Arden ratio. However, the reduced EOG Arden ratio was not necessarily linked to the severity of visual field constriction: Patient 2 had a normal visual field and an EOG Arden ratio of 151 in both eyes, whereas Patient 17 had severe visual field constriction and EOG Arden ratios of 148 and 145. In addition, no linear relationship between static perimetry mean defect and EOG Arden ratio could be demonstrated (figure 2).

Electroretinography. No amplitude or implicit time changes of a- and b-wave responses were found in any patient. ERG oscillatory potentials (OP) were impaired in both eyes in 10 patients (figure 3); 8 had low EOG Arden ratios and 2 had a normal EOG. All other ERG recordings in photopic and scotopic conditions were found to be normal in all patients.

Results in patients treated with a combination of vigabatrin and valproate. All three patients treated with valproate associated with vigabatrin had visual complaints, compared with 2 out of 10 patients receiving vigabatrin alone or a combination of carbamazepine and vigabatrin. Two patients treated with valproate and vigabatrin had a severe peripheral constriction; the third could not perform a visual field. Among the four patients treated with vigabatrin alone, only one presented with severe visual field constriction. All three patients currently treated with valproate had abnormal EOG recordings.

Discussion. In the current study of 20 consecutive patients treated with vigabatrin for more than 6 months, retinal electrophysiologic impairment could be demonstrated in 17 patients (85\%), consisting of reduced EOG Arden ratios (7 patients), altered oscillatory potentials ( 2 patients), or abnormalities in both electrophysiologic tests (8 patients). However, only 12 patients had visual field impairment and among them only 5 complained of visual disturbance. EOG appeared to be the most sensitive test: abnormal results were found in 14 of 20 patients (70\%). EOG Arden ratio was clearly below $185 \%$ in one eye of one patient and in both eyes of 13 patients.

The majority of reports of vigabatrin-associated visual changes do not mention EOG testing. Harding reported subnormal EOG findings in two cases. ${ }^{4}$

The most severe visual impairments could be 


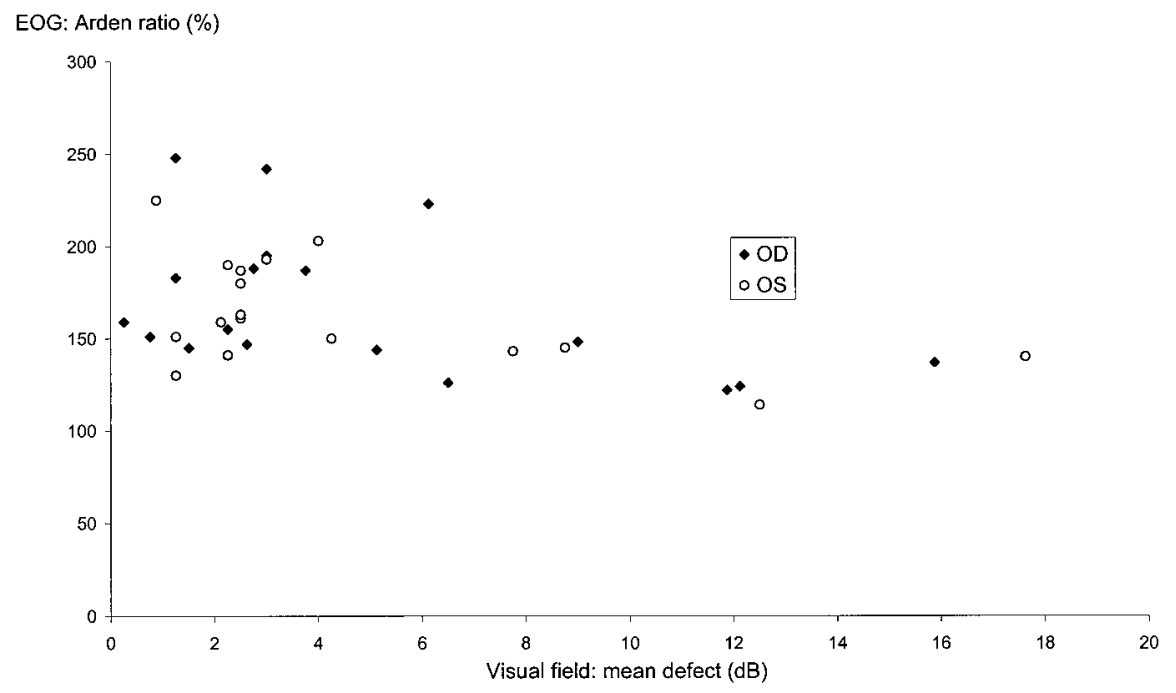

Figure 2. Electro-oculogram results (Arden ratio) plotted against visual field changes (mean defect). $O D=$ right eye; $O S=$ left eye.

found in the patients treated with valproate, who all reported visual symptoms. In addition, these patients demonstrated low EOG Arden ratios, and in two out of three patients, no ERG OP responses could be recorded. In contrast, only a small percentage of patients not on valproate therapy reported visual disturbance.

This possible implication of valproate in association with vigabatrin also appeared in the reports of $\mathrm{Eke}^{5}$ and Wilson, ${ }^{6}$ each of whom reported one severe case. In these patients, vigabatrin and valproate were associated with marked impairment of EOG findings and structural changes at the level of the RPE. Global retinal function as tested by ERG appeared to be normal or subnormal in those patients.

EOG is the major test for evaluating the RPE and the RPE-photoreceptor outer segment complex in patients receiving vigabatrin, even in cases without visual complaints. However, it is not necessarily linked to visual field constriction.

$\mathrm{RPE}$ is actively implicated in generation of the EOG potential. The reduced EOG response could be related to the existence of a GABA transporter located on the apical membrane (subretinal side) of the $\mathrm{RPE},{ }^{12}$ as vigabatrin has proven experimentally to increase GABA levels within the subretinal space. ${ }^{1}$ As spatial distribution of retinal ionic currents are not homogenous, ${ }^{15}$ GABA-induced electrophysiologic changes might occur predominantly in the peripheral pigment epithelium, thus disturbing peripheral photoreceptor function. This might account for peripheral visual field loss found in patients treated with vigabatrin. The hypothesis of primary involvement of the RPE is supported by the association of normal ERG (excepting ERG OP) and abnormal EOG findings, as encountered in Best's vitelliform macular dystrophy. ${ }^{16}$

ERG OP were not recordable in $50 \%$ of patients. OP appear as oscillations on the ascending portion of the b-wave of the ERG (see figure 2). They are believed to be related to the highly GABAergic amacrine cells. They are found to be altered in diseases affecting the midretinal layers, such as diabetes, ${ }^{17}$ but also in patients treated only with carbamazepine. ${ }^{4}$ Among our patients, altered ERG OP was the only abnormal ERG finding detected. In a recent series of 38 patients treated with vigabatrin, ${ }^{11} 4$ patients with visual symptoms were found to have abnormal ERG oscillatory responses suggestive of midretinal dysfunction. Patients without visual

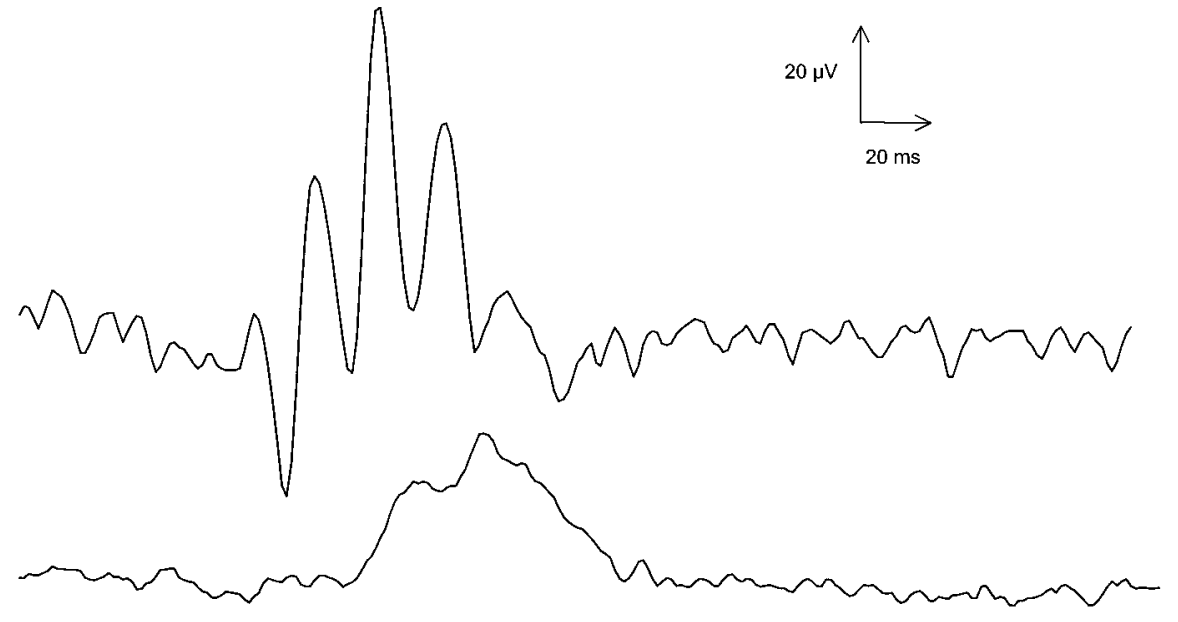

Figure 3. Electroretinogram oscillatory potentials: normal in Patient 3 (top), nonrecordabe in Patient 1 (bottom). 
symptoms were not evaluated. Among the 20 current patients, 5 presented with visual symptoms, no ERG OP could be recorded in 4, and in 1 patient, ERG OP were found to be normal. Asymptomatic patients also had abnormal clinical, perimetric, and electrophysiologic findings. In all 20 consecutive patients treated with vigabatrin, either one of the performed visual fields or electrophysiologic examinations were found to be pathologic. Among the seven patients with abnormal ERG OP, only four had visual complaints. Although the number of patients included may be too small to draw general conclusions, testing only symptomatic patients appears to be insufficient to detect early retinal changes.

Vigabatrin is a useful AED, but our study and previous reports suggest that it can lead to significant visual impairment. From a physiologic point of view, there is no reason why the effects of GABA on the midretinal layers and on the RPE should not be reversible. A combined effect of increased retinal concentration of GABA either with a direct toxicity of vigabatrin or other AED (e.g., valproate) should be considered as a possible mechanism. The question remains at what stage of visual impairment discontinuing vigabatrin is indicated. Another option would be to first discontinue other medications such as valproate in patients with multitherapy regimens. Our results seem to indicate that combination therapy is more toxic than therapy with vigabatrin alone.

The question of reversibility of the observed changes remains. As mentioned, EOG changes could precede severe visual field impairment in some cases. A larger population sample and a thorough long-term follow-up is necessary to evaluate the predictive value of the electrophysiologic tests for the further course of visual impairment.

\section{Acknowledgment}

The authors thank Dr. Teresa Magone for her help in the preparation of the manuscript, Mrs. Daniele Basset for collecting the data, and Mr. Jean-Marie Jacquesson for his advice on statistics.

\section{References}

1. John RA, Rimmer EM, Williams J, Cole G, Fowler LJ, Richens A. Micro-vacuolation in rat brains after long term administra- tion of GABA-transaminase inhibitors. Comparison of effects of ethanolamine-O-sulphate and vigabatrin. Biochem Pharmacol 1987;36:1467-1473.

2. Gibson JP, Yarrington JT, Loudy DE, Gerbig CG, Hurst GH, Newberne JW. Chronic toxicity studies with vigabatrin, a GABA-transaminase inhibitor. Toxicol Pathol 1990;18:225238.

3. Mauguiere F, Chauvel P, Dewailly J, Dousse N. No effect of long-term vigabatrin treatment on central nervous system conduction in patients with refractory epilepsy: results of a multicenter study of somatosensory and visual evoked potentials. PMS Study Multicenter Group. Epilepsia 1997;38:301308.

4. Harding GF. Severe persistent visual field constriction associated with vigabatrin. Four possible explanations exist. BMJ 1997;314:1694. Letter.

5. Eke T. Severe persistent visual field constriction associated with vigabatrin. BMJ 1997;314:180-181. Letter.

6. Wilson EA. Severe persistent visual field constriction associated with vigabatrin. Chronic refractory epilepsy may have role in causing these unusual lesions. BMJ 1997;314:1693. Letter.

7. Backstrom JT. Severe persistent visual field constriction associated with vigabatrin. Manufacturers have started several studies. BMJ 1997;314:1694-1695. Letter.

8. Blackwell N. Severe persistent visual field constriction associated with vigabatrin. Patients taking vigabatrin should have regular visual field testing. BMJ 1997;314:1694. Letter.

9. Wong IC. Severe persistent visual field constriction associated with vigabatrin. Reaction might be dose dependent. BMJ 1997;314:1693-1694. Letter.

10. Harding GF. Severe persistent visual field constriction associated with vigabatrin. Benefit:risk ratio must be calculated for individual patients. BMJ 1998;316:232-233. Letter.

11. Krauss GL, Johnson MA, Miller NR. Vigabatrin-associated retinal cone system dysfunction: electroretinogram and ophthalmologic findings. Neurology 1998;50:614-618.

12. Peterson WM, Miller SS. Identification and functional characterization of a dual GABA/taurine transporter in the bullfrog retinal pigment epithelium. J Gen Physiol 1995;106:10891122 .

13. Marmor MF, Zrenner E. Standard for clinical electrooculography. International Society for Clinical Electrophysiology of Vision. Arch Ophthalmol 1993;111:601-604.

14. International Standardization Committee. Standard for Clinical Electroretinography. Arch Ophthalmol 1989;107:816-819.

15. Burke JM, McKay BS, Jaffe GJ. Retinal pigment epithelial cells of the posterior pole have fewer $\mathrm{Na} / \mathrm{K}$ adenosine triphosphatase pumps than peripheral cells. Invest Ophthalmol Vis Sci 1991;32:2042-2046.

16. Krill AE, Morse PA, Potts AM, Klien BA. Hereditary vitelliruptive macular degeneration. Am J Ophthalmol 1966;61: 1405-1415.

17. Bresnick GH, North K, Groo A. Electroretinographic oscillatory potentials predict progression of diabetic retinopathy: preliminary report. Invest Ophthalmol Vis Sci 1984;25:128. 